\title{
Tribology of particles in acoustic field
}

\section{Vekteris, D. Ozarovskis, R. Zaremba, V. Mokšin}

Vilnius Gediminas Technical University, Department of Machine Engineering,

Basanavičiaus str. 28, 03224, Vilnius, LITHUANIA, Phone: +370 5 2744734, Fax. +370 52745043 ,

E-mail:vekteris@vgtu.lt; darius.o@vilpra.lt; roliuxas@gmail.com;vadim@vgtu.lt.

crossref $\mathrm{http}: / / \mathrm{dx}$.doi.org/10.5755/j01.u.66.3.653

\begin{abstract}
This paper analyzes tribological aspects of particle adhesion in presence of acoustic field. It is shown that acoustic field forces create favourable conditions for contact and adhesion between particles.
\end{abstract}

Keywords: acoustic field, acoustic agglomeration, particle, adhesion.

\section{Introduction}

It is considered that stability of the atoms in the crystal lattice is determined by the ratio of attractive and repulsive forces [1-3]. When the particle begins to move with respect to another particle, molecular attractive and repulsive forces can occur between particles. Then conditions for a particle to be in mechanical equilibrium according Tomlinson [3] can be presented as follows: $\sum F_{i}=\sum F_{p}+F_{N}$, where $\sum F_{i}$ is the component of repulsive forces; $\sum F_{p}$ is the component of attractive forces; $F_{N}$ is the normal force. If the acoustic field is acting on the particles, $\sum F_{p}$ forces are small as compared with the pressure force $F_{N}$, microdisplacements of particles results in friction forces that maintain the equilibrium between attractive and pressure forces.

Microdisplacements between particles produce $n_{k}$ molecular interactions [3]. Moreover, Amonton's law must be satisfied: $f=$ const where $f$ is the friction coefficient. Some authors [3, 4] assume that the number of pairs of interacting molecules $n_{m}$ depends on an effective contact area between colliding particles. Therefore it is possible to calculate the friction coefficient $f$ and the friction force $F_{T}$. However, one problem exists: how to calculate the effective contact area. Author [5] which investigated molecular nature of friction (introduced by Deriagin [1]) also proposed such friction force equation: $F_{T}=A_{r}^{10 / 11}\left(C_{D_{1}}+C_{D_{2}} p_{r_{i}}^{10 / 11}\right)$, where $C_{D_{1}}$ and $C_{D_{2}}$ are the coefficients depending on a surface roughness, elastic properties and molecular structure of the friction surfaces; $p_{r_{i}}$ is the effective pressure at the contact spot; $A_{r}$ is the effective contact area.

However the molecular theory of friction considers molecular interaction forces as sole source of forces. In presence of acoustic field [6-12] impressed pressure forces acts on the particles, it is also known that surfaces of these particles are not ideal. Therefore particle adhesion can have another nature. In this work we shall try to establish the influence of the acoustic forces on particle adhesion.

\section{Object of investigation}

Interactions of the $\mathrm{SiO}_{2}$ particles [13] in presence of an acoustic field were studied. The interaction scheme is presented in Fig. 1.

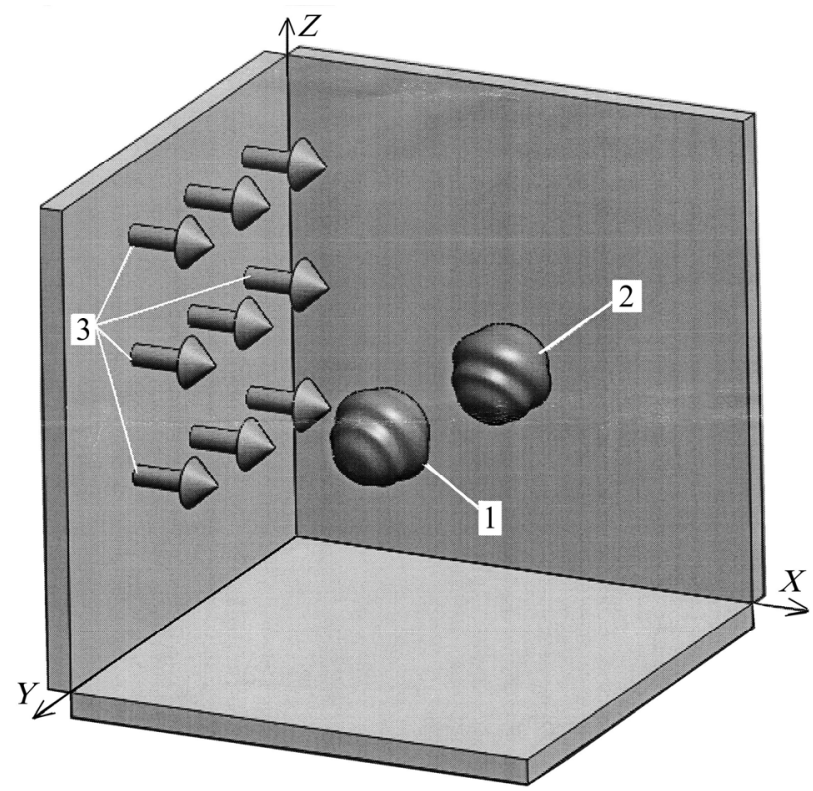

Fig. 1. Interaction of particles in an acoustic field: 1,2 - particles; 3 direction of acoustic field

\section{Mathematical analysis}

Motion of two particles in the air flow acted on by a plane acoustic wave can be described by the following differential equation:

$$
m_{i} \frac{d V_{p_{i}}}{d t}=6 \pi \mu r_{i}\left(V_{f}-V_{p_{i}}\right)
$$

where $i=1,2 ; m_{i}$ is the mass of the particle; $V_{p_{i}}$ is the velocity of the particle; $t$ is the time; $\mu$ is the dynamic viscosity of the air; $r_{i}$ is the radius of the particle; $V_{f}$ is the velocity of air flow.

The velocity of air flow can be calculated as follows: 


$$
V_{f}=u_{f} \cos \omega t
$$

where $u_{f}=A_{f} \omega ; A_{f}$ is the amplitude of the acoustic field; $\omega$ is the angular frequency of the acoustic field.

Substituting Eq. 2 into Eq. 1, we can obtain solution of Eq. 1:

$$
\begin{aligned}
& x_{p_{i}}=A_{f} \frac{6 \pi \mu r_{i} / m_{i}}{(2 \pi f)^{2}+\left(\frac{6 \pi \mu r_{i}}{m_{i}}\right)^{2}} \times \\
& \times\left(\frac{6 \pi \mu r_{i}}{m_{i}} \sin (2 \pi f t)-2 \pi f \cos (2 \pi f t)\right),
\end{aligned}
$$

where $x_{p_{i}}$ is the displacement of the particle; $f$ is the frequency of acoustic field; $t$ is the time.

It can be written:

$$
m_{i}=\rho_{i} V_{i}
$$

where $\rho_{i}$ is the mass of the particle; $V_{i}$ is the volume of the particle.

It can be adopted that:

$$
V_{i}=\frac{4}{3} \pi r_{i}^{3}
$$

By substituting Eqs. 4 and 5 into Eq. 3 and rearranging we obtained:

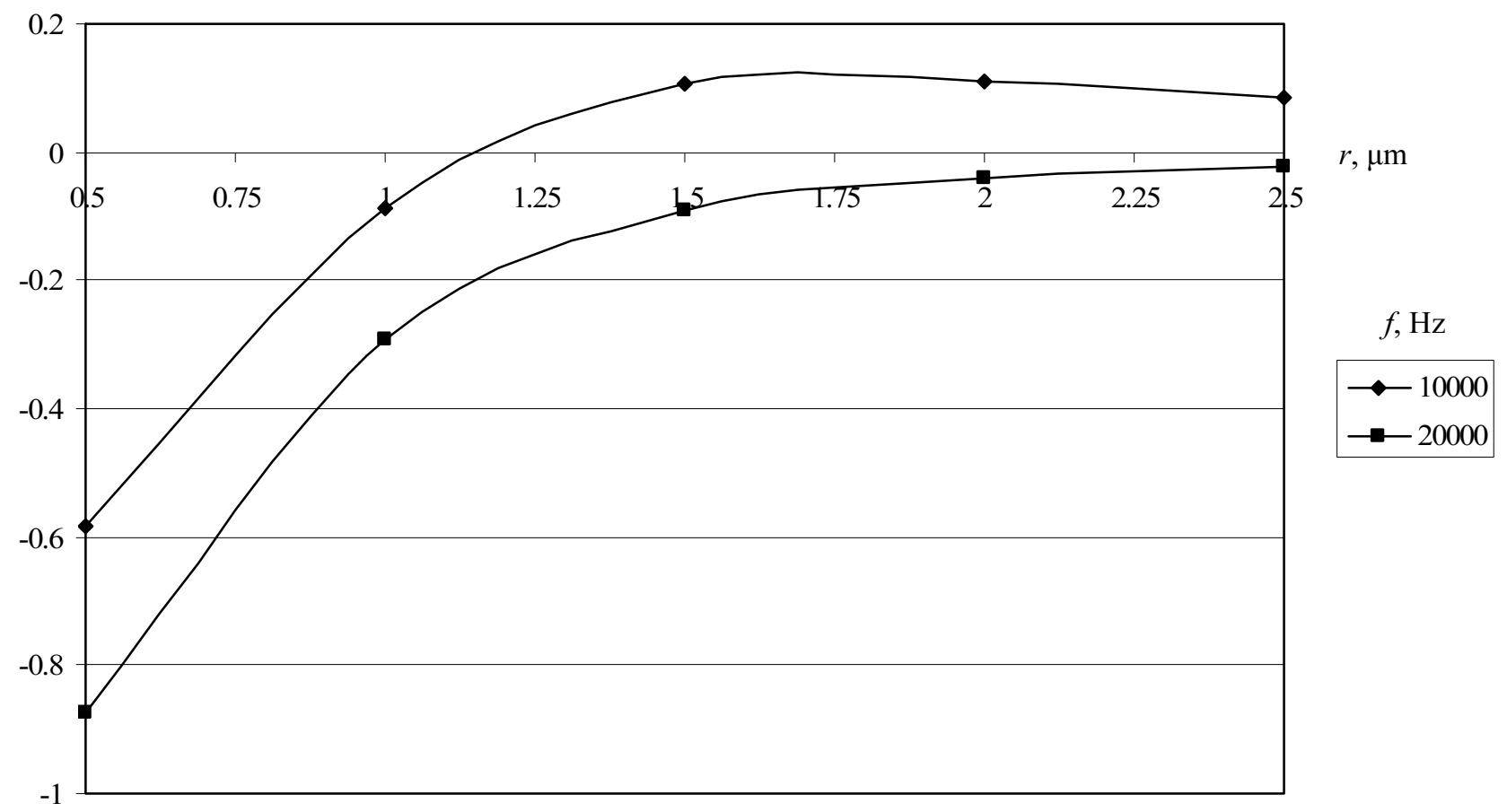

Fig. 2. Dimensionless parameter $x_{p} / A_{f}$ as function of quartz sand particle radius $r: \rho=1201 \mathrm{~kg} / \mathrm{m}^{3} ; \mu=17.8 \times 10^{-6} \mathrm{~Pa} / \mathrm{s} ; t=2 \mathrm{~s}$ 

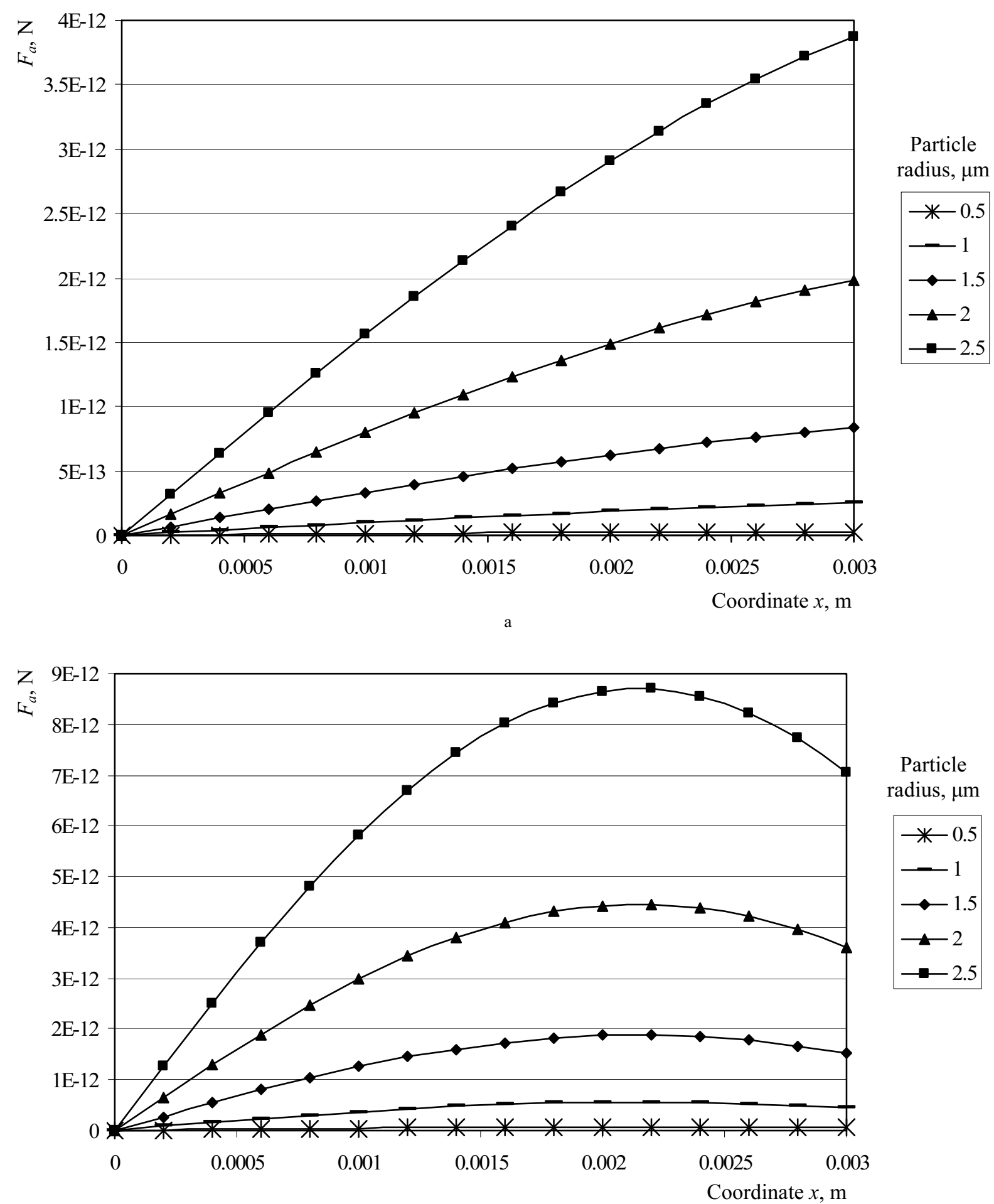

b

Fig. 3. Acoustic field force $F_{a}$ as function of coordinate $x$ and radius of the particle: a $\left.-f=10 \mathrm{kHz}, J=100000 \mathrm{~W} / \mathrm{m}^{2} ; \mathrm{b}\right)-f=20 \mathrm{kHz}$, $=100000 \mathrm{~W} / \mathrm{m}^{2}$

\section{Experimental investigation}

Photo of experimental stand is presented in Fig. 4. Two acoustic field generators were mounted inside the stand.
1-5 $\mu \mathrm{m} \mathrm{SiO}_{2}$ particles were used for investigations. The microscope image of the particles is shown in Fig. 5. Microscope images of aggregated particles after the action of the acoustic field are presented in Fig. 6 and 7. 
ISSN 1392-2114 ULTRAGARSAS (ULTRASOUND), Vol. 66, No. 3, 2011.

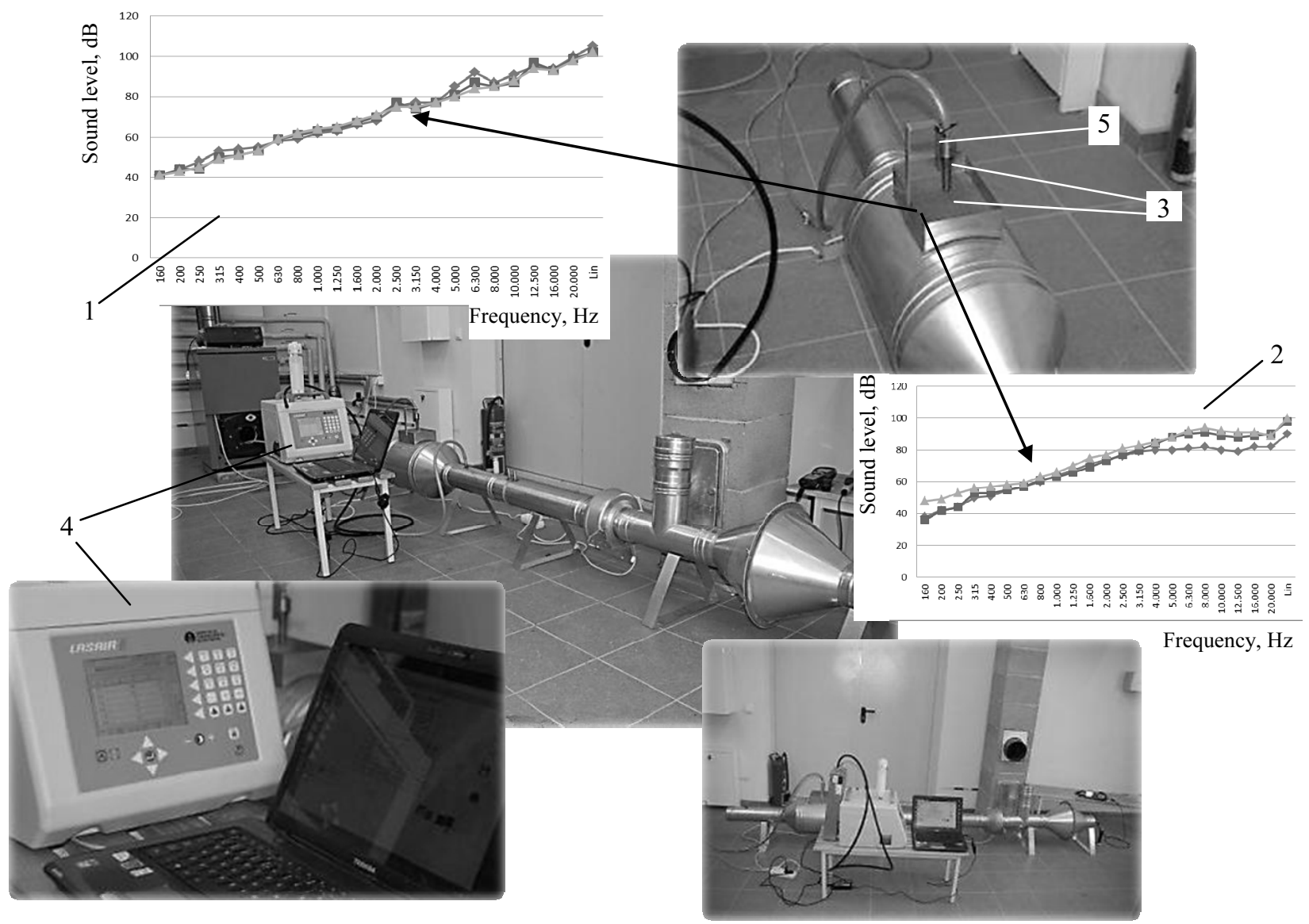

Fig. 4. Experimental stand: 1, 2 - characteristics of acoustic field generators; 3 - acoustic field generator mounting places; 4 -particle detecting and counting system "Lasair II"; 5 - integrated analyzer

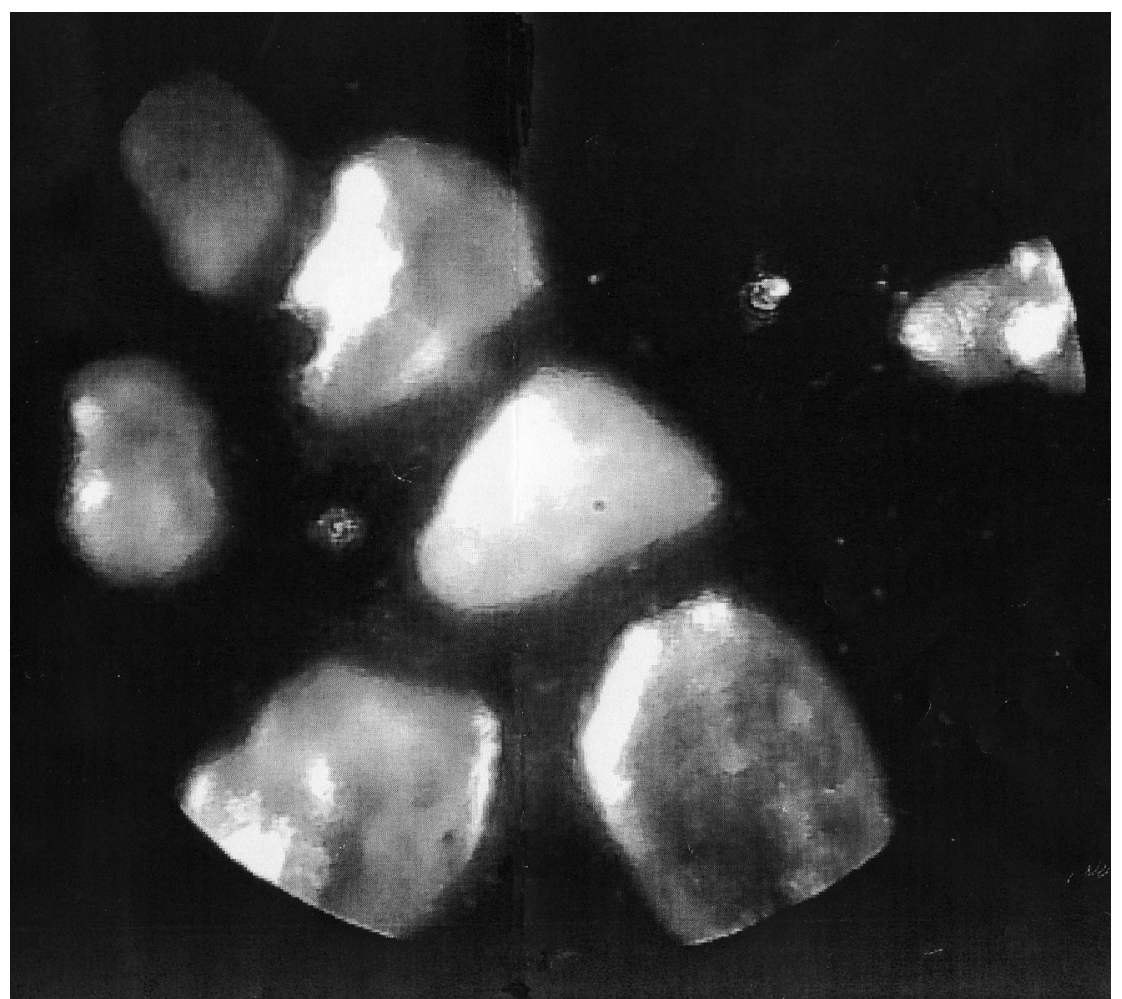

Fig. 5. Microscope image of $\mathrm{SiO}_{2}$ particles before the acoustic field was applied 


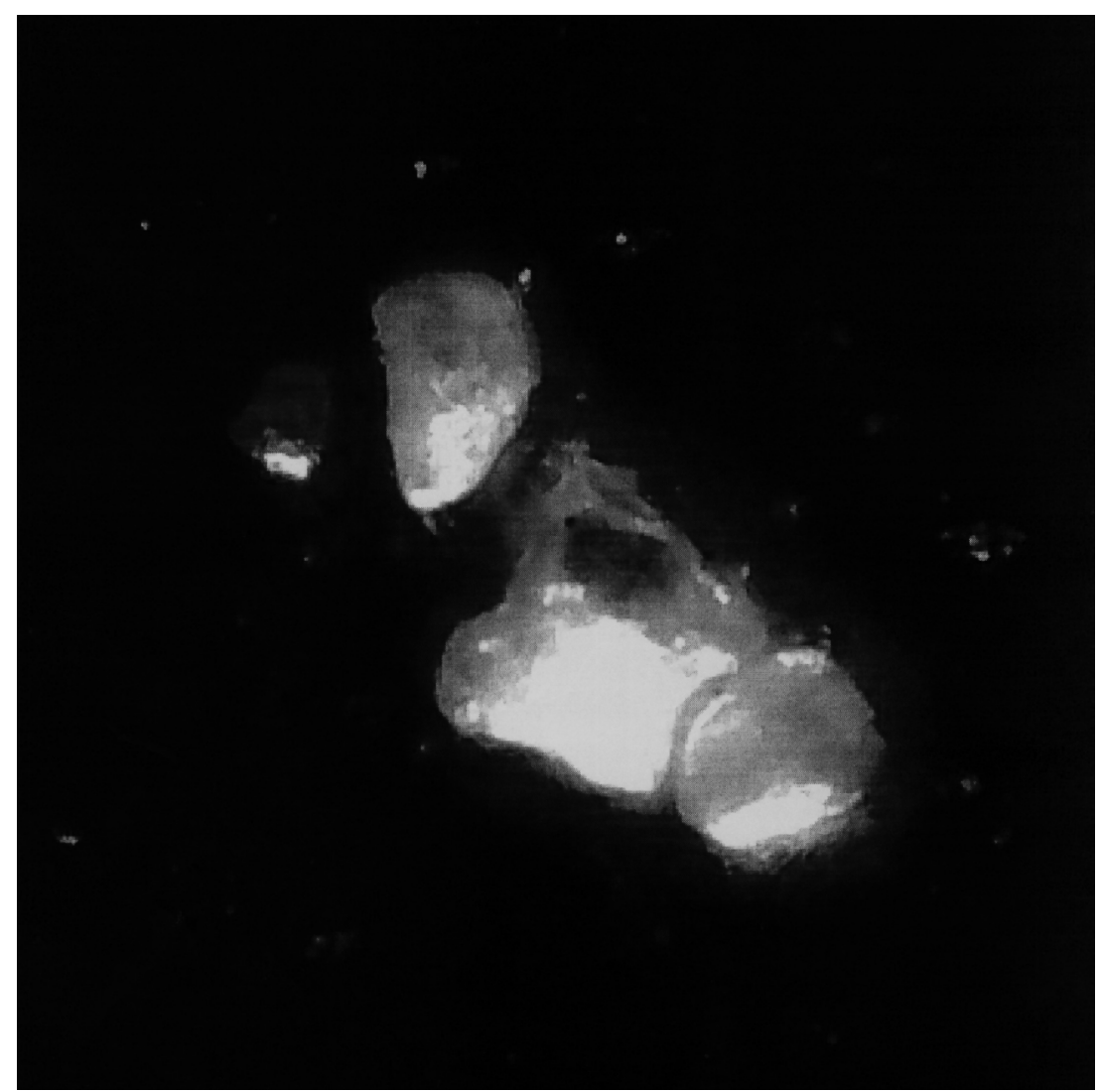

Fig. 6. $\mathrm{SiO}_{2}$ aggregated particles after the action of acoustic field

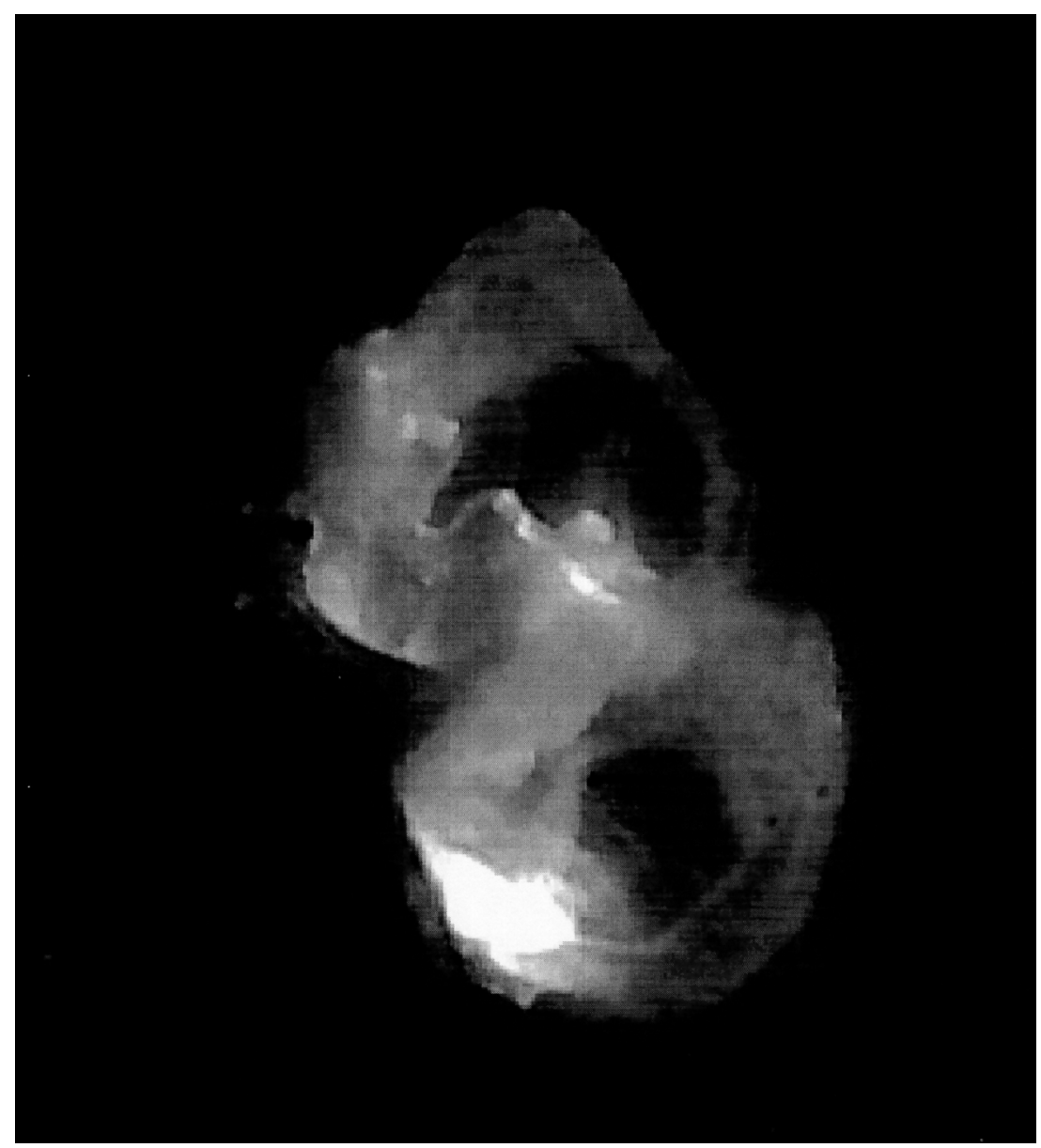

Fig. 7. $\mathrm{SiO}_{2}$ particles adhesion caused by the action of acoustic field 


\section{Conclusions}

1. The obtained results show that interactions and adhesion between coarser particles can be sufficiently increased if particles are acted on by audio-frequency acoustic field.

2. From the experimental results it is evident that tangential interactions take place between particles.

3. It is purposeful to arrange acoustic sources in such a way that both normal and tangential forces would act on the particles.

\section{References}

1. Deriagin B. V., Krotova N. A. Adhesion. Publishing house of academy of sciences of USSR. Moscow. 1949. P.244 (in Russian).

2. Cotrell A. H. Theory of crystal dislocations. Moscow. Mir. 1969. P.96. (in Russian).

3. Shaw P. E., Leavey E. W. L. Friction of dry solids in vacuo. Phil. Mag. 1930. Vol.10. P.809-822.

4. Kontorova T. A. Friction of dry surfaces. Uspekhi Fizicheskikh Nauk. 1937. T.XVIII, Iss.3. P.346-391.

5. Schedrov V. S. To the molecular theory of the friction. Zhurnal tekhniceskoj fiziki. 1947. T.XVII, Iss.5. P.537-542.

6. Caperan Ph., Somers J., Richter K., Fourcaudot, S. Acoustic agglomeration of titanium dioxide aggregates as a function of acoustic power. J Aerosol Sci. 1995. Vol.26, No.1. P.277-278.

7. Gonzalez-Gomez I., Hoffmann T.L., Gallego-Juarez J.A. Theory and calculation of sound induced particle interactions of viscous origin. Acta Acustica. 2000. Vol.86. No5. P.784-797.
8. Hoffmann T. L., Chen W., Koopmann G. H., Scarioni A. W., Song L. Experimental and numerical analysis of bimodal acoustic agglomeration. J Vib Acoust. 1993. Vol.115. Iss.3. P.232-240.

9. Riera-Franco de Sarabia E., Elvira-Segura L., Gonzalez-Gomez I., Rodriguez-Maroto J. J., Munoz-Bueno R., Dorronsoto-Areal J. L. Investigation of the influence of humidity on the ultrasonic agglomeration of submicron particles in diesel exhausts. Ultrasonics. 2003. Vol.41. Iss.4. P.277-281.

10. Riera-Franco de Sarabia E., Gallego-Juarez J. A., RodriguezCorral G., Elvira-Segura L., Gonzalez-Gomez I. Application of high-power ultrasound to enhance of fluid/solid particle separation process. Ultrasonics. 2000. Vol.38. P.642-646.

11. Temkin S. Elements of acoustics. John Wiley \& Sons Inc. 1981. P.528.

12. Bergman L. Ultrasound and its application in science and technique. Publishing house of foreign literature, Moscow. 1957. P.728 (in Russian).

13. Vekteris V., Striška V., Mokšin V., Ozarovskis D. Study of the interaction between particles in the acoustic cyclone separator. Ultragarsas. 2011. Vol.66. No1. P.49-53.

\section{Vekteris, D. Ozarovskis, R. Zaremba, V. Mokšin}

\section{Dalelių tribologija akustiniame lauke}

\section{Reziumè}

Straipsnyje nagrinejjami dalelių sukibimo akustiniame lauke tribologiniai aspektai. Parodyta, kad akustinio lauko jègos sudaro palankias sąlygas dalelių kontaktui ir sukibimui.

Pateikta spaudai 20110608 